\title{
Comment on " $R$ ip current related drowning deaths and rescues in Australia 2004-2011" by Brighton et al. (2013)
}

\author{
B. C. Brewster and R. Gould \\ United States Lifesaving Association, Huntington Beach, California, USA \\ Correspondence to: B. C. Brewster (brewster@lifesaver1.com)
}

Received: 12 December 2013 - Published in Nat. Hazards Earth Syst. Sci. Discuss.: 24 April 2014

Revised: 23 July 2014 - Accepted: 8 August 2014 - Published: 27 August 2014

In their article, "Rip current related drowning deaths and rescues in Australia 2004-2011", the authors endeavored to estimate the percent of surf beach rescues and drowning deaths that can be attributed to rip currents. In doing so, they misinterpreted data we of the United States Lifesaving Association provided to them and thus grossly understated the proportion of rescues from drowning at surf beaches in the USA that are primarily attributed to rip currents. While they reported $53.7 \%$, the numbers actually range from 80 to $90 \%$ according to our data.

To understand the bases of their errors, one may first consider a very logical step Brighton et al. took with respect to data they gleaned from Australian rescue statistics. Specifically they note that those rescues, "... that were described to be at a location other than a surf beach have been removed for this analysis $(n=198)$, because the locations are unaffected by rip currents". Unfortunately, they did not apply a similar vetting with respect to the US data, which also includes non-surf beaches that should be excluded.

More significantly, in reviewing the Australian rescue data Brighton et al. found that the majority of the rescue reports do not include a primary cause and thus they excluded them. U1timately they considered only a small subset which they define as "major" rescues $(n=1246)$ and for which the reports are more detailed, although even those reports do not appear to reliably include a primary cause. In the US, a significant number of reporting agencies (typically government-funded lifeguard providers) routinely tabulate the cause of rescue, including rip currents, for all rescues. However, some reporting agencies in our data do not. Unfortunately, Brighton et al. included all of the US rescue numbers, without excluding the data from agencies which do not report a primary cause (as they had endeavored to do with Australian data).
One of these reporting agencies, for example, consistently reports over 10000 rescues per year, but does not provide a breakdown of causation.

We have reviewed rescue reports contained in United States Lifesaving Association Statistics (2013) for a comparable period (2004 to 2011) to that studied by Brighton et al. (2013) at our surf beaches which reported a primary cause of rescue. Of these $(n=343246), 81 \%$ were reported as being primarily attributable to rip currents. In some areas of the US, this percentage is higher. For example, an analysis of California State Parks rescue data from 2004 to 2011, which relies on a Scantron system to record each rescue, finds that $85 \%$ had "rip current" as the primary cause. This includes an indeterminate number of rescues at inland beaches without rip currents, which skews the rip current percent downward. Studies of Southern California agencies have found even higher percentages.

We wonder why surf beach rescues in Australia would be less likely to be attributable to rip currents than surf beach rescues in the US, or if there may be other vulnerabilities in the data analysis of Brighton et al. that found only a $57.4 \%$ attribution to rip currents in Australia.

Acknowledgements. B. Chris Brewster is President of the United States Lifesaving Association (USLA). Rick Gould is Statistics Coordinator for the USLA.

Edited by: I. Didenkulova

Reviewed by: A. Wooler and two anonymous referees 


\section{References}

Brighton, B., Sherker, S., Brander, R., Thompson, M., and Bradstreet, A.: Rip current related drowning deaths and rescues in Australia 2004-2011, Nat. Hazards Earth Syst. Sci., 13, 1069 1075, doi:10.5194/nhess-13-1069-2013, 2013.
United States Lifesaving Association Statistics - USLA: http:// www.usla.org/statistics, last access: 18 November 2013. 